\title{
ElectronixTutor Integrates Multiple Learning Resources to Teach Electronics on the Web
}

\author{
Brent Morgan \\ University of Memphis \\ Memphis, TN, USA \\ brent.morgan.phd@gmail.com
}

\author{
Andrew Tackett \\ University of Memphis \\ Memphis, TN, USA \\ andrew.tackett@gmail.com
}

\author{
Andrew J. Hampton \\ University of Memphis \\ Memphis, TN, USA \\ ajhampton0524@gmail.com
}

\author{
Lijia Wang \\ University of Memphis \\ Memphis, TN, USA \\ wlj54188@gmail.com
}

\author{
Zhiqiang Cai \\ University of Memphis \\ Memphis, TN, USA \\ zhiqiang.cai.2016@gmail.com
}

\author{
Xiangen Hu \\ University of Memphis \\ Memphis, TN, USA \\ xiangenhu@gmail.com
}

\author{
Arthur C. Graesser \\ University of Memphis \\ Memphis, TN, USA \\ art.graesser@gmail.com
}

\begin{abstract}
ElectronixTutor is a new Intelligent Tutoring System for electronics that integrates multiple intelligent learning resources, including AutoTutor, Dragoon, LearnForm, ASSISTments, and BEETLE-II, as well as Point \& Query hotspots on diagrams and numerous text documents on the subject of electronics. ElectronixTutor's student model contains a set of electronics knowledge components (e.g., "transistor behavior"), each of which are taught by multiple learning resources. ElectronixTutor also features a recommender system, which suggests topics and resources for the student to try based on the student model. ElectronixTutor uses a Moodle interface, and is accessible to anyone via a web browser. Currently, ElectronixTutor is being tested by undergraduate electronics students before supplementing Naval Apprentice Technician Training coursework in the fall of 2018.
\end{abstract}

\section{Author Keywords}

Intelligent Tutoring Systems; STEM Education; Electronics; computer agents; AutoTutor; Dragoon.

\section{ACM Classification Keywords \\ Computing methodologies---Artificial Intelligence--- Natural Language Processing---Discourse, dialogue and}

Permission to make digital or hard copies of all or part of this work for personal or classroom use is granted without fee provided that copies are not made or distributed for profit or commercial advantage and that copies bear this notice and the full citation on the first page. Copyrights for components of this work owned by others than the author(s) must be honored. Abstracting with credit is permitted. To copy otherwise, or republish, to post on servers or to redistribute to lists, requires prior specific permission and/or a fee. Request permissions from Permissions@acm.org.

L@S 2018, June 26-28, 2018, London, United Kingdom

(C) 2018 Copyright is held by the owner/author(s). Publication rights licensed to ACM.

ACM ISBN 978-1-4503-5886-6/18/06 ..\$15.00

https://doi.org/10.1145/3231644.3231691 pragmatics; 500 and Computing methodologies--Artificial Intelligence---Distributed artificial intelligence-- Intelligent agents; 500

\section{ELECTRONIXTUTOR}

The Office of Naval Research (ONR) created a STEM challenge initiative to encourage teams to develop and test an intelligent tutoring system (ITS) in a limited amount of time (18 months). From several dozen applications, four teams were selected: The University of Memphis, Arizona State University, BBN/Raytheon, and a collaboration between the University of Massachusetts and Worcester Polytechnic Institute. These teams reported their findings and competed for another round of funding to focus on a Navy-relevant STEM topic. The ONR selected analog electronic circuits as the subject matter for the second wave of funding. The University of Memphis was selected to take the lead in developing an ITS on electronic circuits, but was asked to integrate electronics content developed by the other teams. In essence, the ITS would be an ensemble of ITS developed by multiple teams on the same topic. Consequently, ElectronixTutor [2] was developed within 18 months, integrating intelligent learning resources provided by all four teams.

The learning resources integrated into ElectronixTutor include AutoTutor (verbal reasoning; [1]), Dragoon (mental model construction and simulation; [4]), LearnForm (a general learning platform for problem-solving), ASSISTments (skill-building; [3]), BEETLE-II (macro-level discourse for basic electronics), and Point \& Query (clickable hotspots on diagrams). Additionally, there are text summaries available for each topic and over 5000 pages of the Navy Electronics and Electricity Training Series (NEETS). Figure 1 shows a screenshot of the user interface (which uses Moodle). 


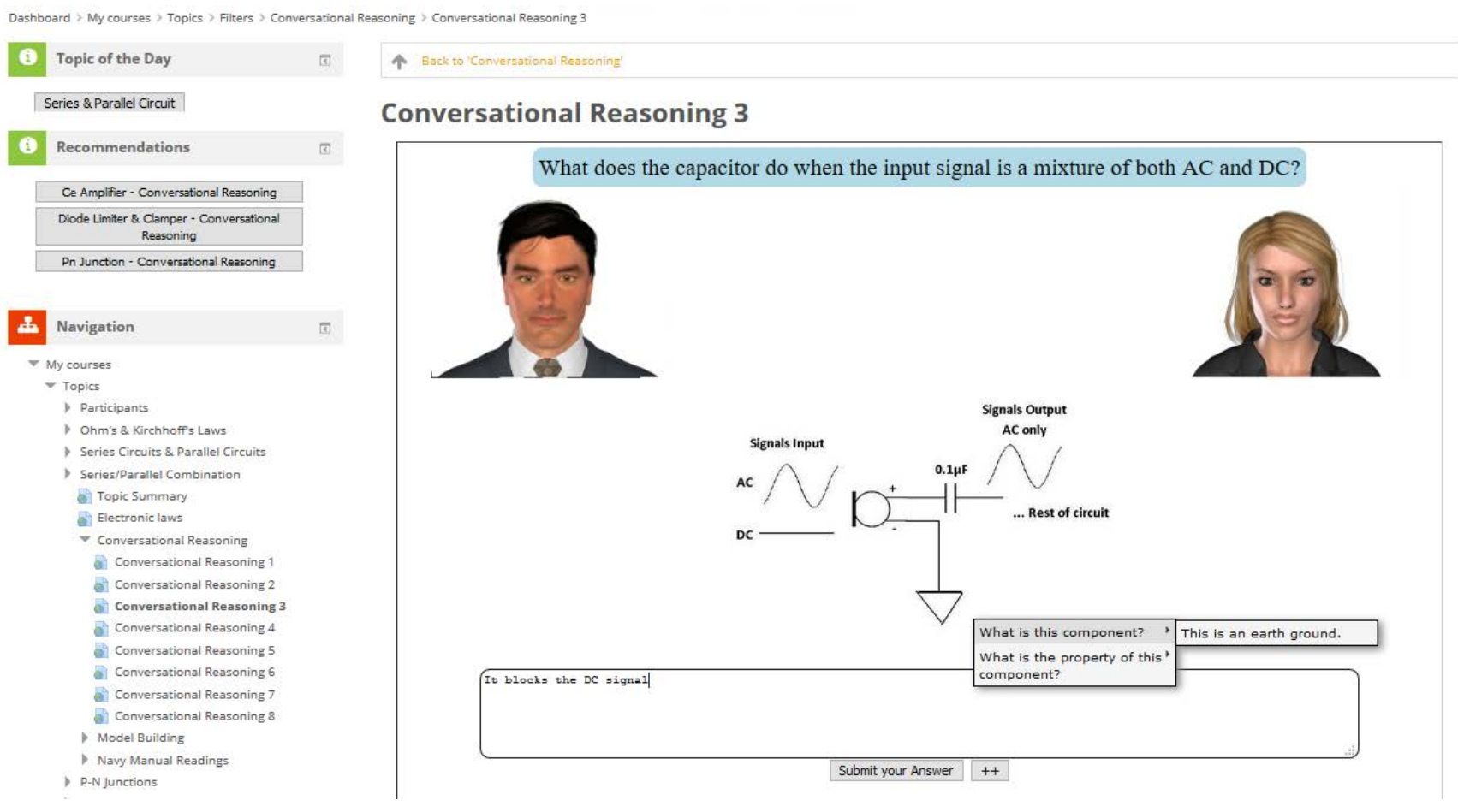

Figure 1. Screenshot of ElectronixTutor user interface, displaying Recommendations and the Navigation toolbar on the left, and AutoTutor and Point \& Query on the right.

ElectronixTutor is currently being tested by undergraduates from at least three universities. The students complete tasks for course credit and/or are paid to complete specific tasks and give feedback. After improving the system based on the students' interactions and feedback, ElectronixTutor will supplement classroom instruction for Naval Apprentice Technician Training in electronics. ElectronixTutor is available on the web at https://et0.x-in-y.com/.

ElectronixTutor will be available for a live interactive demonstration at Learning At Scale 2018. An ElectronixTutor team member will be available to give a demonstration, or visitors can interact with the system themselves with a provided laptop computer or their own device. While interacting with the system, one or more team members will be available to discuss the system, answer questions, etc.

\section{ACKNOWLEDGMENTS}

The research on was supported by the Office of Naval Research (N00014-00-1-0600, N00014-15-P-1184; N00014-12-C-0643; N00014-16-C-3027) and the National Science Foundation Data Infrastructure Building Blocks program (ACI-1443068). Any opinions, findings, and conclusions or recommendations expressed in this material are those of the authors and do not necessarily reflect the views of ONR or NSF.

\section{REFERENCES}

1. Arthur C. Graesser. 2016. Conversations with AutoTutor help students learn. Int J Artif Intell Educ, $26,124-132$.

2. Arthur C. Graesser, Xiangen Hu, Benjamin D. Nye, Kurt VanLehn, Rohit Kumar, Cristina Heffernan... \& Frank Andrasik. 2017. ElectronixTutor: an intelligent tutoring system with multiple learning resources for electronics. Int J STEM Educ, doi: 10.1186/s40594017-0072-5

3. Neil Heffernan and Cristina Heffernan. 2014. The ASSISTments ecosystem: building a platform that brings scientists and teachers together for minimally invasive research on human learning and teaching. Int $J$ Artif Intell Educ, 24, 470-497

4. Kurt VanLehn, Greg Chung, Sachin Grover, Ayesha Madni, Jon Wetzel. 2016. Learning science by constructing models: can Dragoon increase learning without increasing the time required? Int J Artif Intell Educ, 26, 4: 1-36. 